\title{
Long-term quercetin supplementation reduces lipid peroxidation but does not improve performance in endurance runners
}

This article was published in the following Dove Press journal:

Open Access Journal of Sports Medicine

II March 2013

Number of times this article has been viewed

\section{Shane D Scholten' \\ Igor N Sergeev ${ }^{2}$}

'Department of Natural Sciences, University of Sioux Falls, Sioux Falls, SD, USA; ${ }^{2}$ Department of Health and Nutritional Sciences, South Dakota State University, Brookings, SD, USA
Correspondence: Shane Scholten University of Sioux Falls,

I I0I W 22nd St, Sioux Falls, SD, USA 57103

Tel + I 60533167 II

Email shane.scholten@usiouxfalls.edu
Purpose: To evaluate the effects of chronic quercetin supplementation on endurance performance and antioxidant status in long distance runners. We hypothesized that an improved antioxidant status can be associated with enhanced performance.

Methods: During 6 weeks of supplementation utilizing a double blind, randomized design, young male subjects received quercetin $(1000 \mathrm{mg}$ /day) or placebo while maintaining their current training schedules.

Results: Following the end of the supplementation period, there was a significant time $\times$ supplement interaction for serum malondialdehyde (MDA), an indicator of lipid peroxidation. There were no significant pre- to post-supplement changes in parameter values employed for measuring total antioxidant capacity, superoxide dismutase activity, and protein oxidation (protein carbonyl) in serum. There were also no significant pre- to post-supplement differences in $\mathrm{VO}_{\text {2peak}}$, running economy, heart rate, and rating of perceived exertion (RPE) during the $10 \mathrm{~km}$ time trial.

Conclusion: The findings obtained indicate that there is a relationship between quercetin supplementation and the statistically significant decreasing trend in MDA levels following 6 weeks of supplementation and training. This evidence suggests that quercetin can reduce oxidative stress (lipid peroxidation). However, performance improvements were not significant (as measured by $\mathrm{VO}_{2 \text { peak }}$, running economy, heart rate, and RPE).

Keywords: quercetin, antioxidant capacity, oxygen consumption, running economy, exercise performance

\section{Introduction}

Quercetin, a flavonoid with high antioxidant activity, is abundant in many commonly consumed fruits and vegetables such as onions, berries, and apples. The typical US diet provides 5-40 mg/day of quercetin, but intake can reach $200-500 \mathrm{mg} /$ day with high fruit and vegetable consumption. ${ }^{1}$ As a polyphenolic flavonoid, quercetin has been shown to be a powerful antioxidant. There is also evidence that quercetin can provide a number of health and performance benefits due to its antiviral, anti-inflammatory, anticarcinogenic, cardioprotective, psychostimulating, and neuroprotective properties. ${ }^{2,3}$ In regards to physical performance, the potential for quercetin to be ergogenic lies in the electron donating capacity of its phenolic hydroxyl groups, reducing the effects of reactive oxygen species (ROS) ${ }^{4}$ and the possibility of increasing mitochondrial density. ${ }^{5}$ Few authors have studied quercetin's effect on human performance, with consistent results being elusive..$^{5-8}$ Reasons for equivocal findings include (1) acute supplement duration; (2) mode of exercise, with cycling having less muscle damage, inflammation, and oxidative stress than running; (3) quercetin cocktails with other 
isoflavones, catechins, vitamin $\mathrm{C}$ and $\mathrm{E}$, and omega-3 fatty acids, not allowing for evaluation of the direct effects of quercetin benefits; ${ }^{4}$ and (4) dose/response variables have demonstrated many factors unique to individuals causing different absorption and storage capacities of quercetin. ${ }^{9}$

Oxidative stress during physical activity can cause damage to lipids, proteins, DNA, and carbohydrates if the increase in free radicals is greater than the ability to neutralize them. Byproducts of lipid and protein oxidation are malondialdehyde (MDA) and protein carbonyls, respectively. To measure the damage to cellular components by oxidation, studies have typically used MDA as a measure of oxidative stress induced by exercise. ${ }^{10}$

Most antioxidant supplementation studies on human performance have been carried out using vitamins $\mathrm{A}, \mathrm{C}$, and $\mathrm{E}$. It has been suggested that antioxidant supplementation may improve performance by reducing oxidative stress to the contractile and structural proteins in muscle, thus limiting the inflammation and fatiguing effects of exercise. ${ }^{11,12}$ Contrary to this suggestion, vitamin $\mathrm{C}$ was found to delay the exercise recovery process and have no positive effect on the delayed onset muscle soreness. ${ }^{13}$

Human performance studies using antioxidant supplementation have been frequently carried out in a maximal exercise capacity such as a long duration race or via maximal oxygen testing. At exercise intensities over $80 \% \mathrm{VO}_{2 \max }$, antioxidant systems become overrun with ROS and no longer provide benefit. ${ }^{14}$ With extensive exercise durations, such as in long distance endurance runs, acute antioxidant supplementation may have no beneficial effect due to absent training effects and short half-life of the antioxidants used.

We found only two studies with a treatment time of at least 6 weeks where the effects of quercetin on endurance performance in humans have been evaluated. MacRae and Mefferd $^{7}$ found a 3\% improvement in cycle time trial performance following 6 weeks of supplementation. This performance improvement was not statistically significant but even a minor improvement for elite cyclists in competition can have a dramatic effect on final race results. It should also be noted that the placebo group in this study had a $1.5 \%$ performance improvement. The study by Bigelman et $\mathrm{al}^{15}$ found no significant difference in $\mathrm{VO}_{2 \text { peak }}$ or anaerobic performance measures with 6 weeks of quercetin supplementation in moderately trained military personnel. Neither of these two studies investigated the antioxidant effects of quercetin supplementation.

Several researchers have studied the acute effects of quercetin supplementation on performance measures..$^{5,16-18}$
Because $\mathrm{VO}_{2 \max }$ and cellular adaptations take several weeks to improve with aerobic exercise training, ${ }^{19}$ it is likely that a similar duration of exercise with quercetin supplementation is warranted to produce significant performance improvements and develop an adaptation response to oxidative stress.

The purpose of this study was to compare the treatment effect of quercetin supplementation to placebo using trained, healthy, male endurance runners during a 6 week time period. To date, no other studies have investigated the antioxidant effects of quercetin in endurance performance over a training period longer than 7 days. First, we hypothesized that quercetin supplementation will result in less oxidative stress at baseline, after a $\mathrm{VO}_{2 \text { peak }}$ test and after a strenuous $10 \mathrm{~km}$ time trial (10 km TT) exercise bout as measured by lipid peroxidation (MDA) and protein oxidation (protein carbonyl) in serum. Second, we hypothesized that 6 weeks of quercetin supplementation and continued exercise training will increase endogenous antioxidant activity as measured by total antioxidant capacity (TAC) and superoxide dismutase (SOD) activity in serum. Lastly, we hypothesized an improved $\mathrm{VO}_{\text {2peak }}$, improved running economy, decreased heart rate, and rating of perceived exertion (RPE) during a $10 \mathrm{~km}$ TT for quercetin supplementation versus placebo.

\section{Methods}

\section{Subjects}

Eight males ages 18-39 volunteered to participate after a preliminary screening and explanation of all procedures and gave their written informed consent, according to the experimental procedures approved by the University of South Dakota, South Dakota State University, and University of Sioux Falls Institutional Review Boards. Subjects were recruited through the local running club and collegiate cross country teams. During the study, subjects were instructed to maintain their current training program and not alter the frequency, intensity, duration, or mode of exercise. Subjects were also instructed to maintain their dietary habits and refrain from any other supplementation.

All volunteers completed a medical history, exercise history, and Physical Activity Readiness Questionnaires at the first visit. All volunteers were required to be able to complete a $10 \mathrm{~km}$ run and have maintained an aerobic exercise program of at least $90-180$ minutes per week at a $65 \%-85 \%$ maximum heart rate intensity for greater than 1 year. Subjects met the American College of Sports Medicine (ACSM) guidelines for apparently healthy individuals. ${ }^{20}$ Volunteers were excluded if they were currently supplementing with quercetin or other antioxidants, female, weighed less than $110 \mathrm{lbs}$, men under the age of 18 or over the age of 45 , and had two or more of the fol- 
lowing ACSM risk factors: family history, cigarette smoking, hypertension, dyslipidemia, impaired fasting glucose, obesity, or sedentary lifestyle. Subjects were required to abstain from vigorous activity for 48 hours prior to the second lab visit.

Subjects were randomly assigned in a double blind manner to a placebo or quercetin group. Treatment started after the completion of the first $10 \mathrm{~km}$ TT and continued for 6 weeks through completion of the second $\mathrm{VO}_{2 \text { peak }}$ and $10 \mathrm{~km}$ TT (Figure 1).

\section{Supplementation}

The quercetin supplement (Jarrow Formulas, Los Angeles, CA, USA) contained $500 \mathrm{mg}$ of quercetin with no other antioxidants, which was confirmed by independent lab analysis (Novatia, Monmouth Junction, NJ, USA). The form of quercetin used was quercetin dihydrate which was found to dose dependently increase plasma concentrations in humans with 2 weeks supplementation. ${ }^{9}$ Davis et $\mathrm{al}^{21}$ found that after ingestion of a single dose of $250 \mathrm{mg}$ or $500 \mathrm{mg}$ quercetin, its peak concentration in the plasma is detected within 2-3 hours and the concentration returns to baseline in 24 hours. Subjects were instructed to take one pill in the morning and one pill in the evening for a total intake of $1000 \mathrm{mg} /$ day. This intake amount was based on previous research regarding safety, bioavailability, and human plasma quercetin concentrations with supplementation. ${ }^{1}$

\section{Experimental procedures}

At the second lab visit, baseline heart rate and blood pressure measurements were taken. Resting and exercise heart rates were measured using a wireless transmitter system (Polar Electro Inc, Woodbury, NY, USA). $\mathrm{VO}_{2 \text { peak }}$ was determined for all subjects using a previously published graded protocol ${ }^{22}$ on a motorized treadmill (TrackMaster Model TMX325C, Full Vision, Newton, KS, USA) with expired gases analyzed using a Med Graphics CPX/D (St Paul, MN, USA) automated metabolic cart. After the $\mathrm{VO}_{\text {2peak }}$ test, subjects were acclimated for the next session's $10 \mathrm{~km}$ TT treadmill run which took place 24-48 hours after the $\mathrm{VO}_{2 \text { peak }}$ test.

During the $10 \mathrm{~km} \mathrm{TT}$, oxygen consumption, heart rate, and RPE values were recorded for one minute intervals at
$3.2 \mathrm{~km}, 6.4 \mathrm{~km}$, and $9.6 \mathrm{~km}$. Subjects were instructed to complete the $10 \mathrm{~km}$ TT at their self-selected race pace. Run speed was recorded throughout the test. At the end of this study, the $10 \mathrm{~km}$ TT was repeated at the exact same run speeds and time as the preliminary $10 \mathrm{~km}$ TT to replicate the same intensity. Oxygen consumption, heart rate, and RPE values were again recorded at $3.2 \mathrm{~km}, 6.4 \mathrm{~km}$, and $9.6 \mathrm{~km}$ and were used to measure the effects of supplementation.

Blood samples were drawn into tubes with no additives prior to the $\mathrm{VO}_{\text {2peak }}$ test (Baseline), immediately post $\mathrm{VO}_{2 \text { peak }}\left(\mathrm{VO}_{2 \text { peak }}\right)$, and immediately post $10 \mathrm{~km} \mathrm{TT}$. Serum was obtained by centrifugation at $2000 \mathrm{~g}$ for 15 minutes. Aliquots of serum were immediately frozen at $-80^{\circ} \mathrm{C}$ until analysis. Serum was analyzed for lipid peroxidation using OxiSelect MDA Adduct ELISA Kit (Cell Biolabs, Inc, San Diego, CA, USA), SOD activity using OxiSelect Superoxide Dismutase Activity Assay (Cell Biolabs, Inc), total antioxidant capacity using Total Antioxidant Capacity Assay Kit (BioVision, Mountain View, CA, USA), and protein carbonyl content was measured using OxiSelect Protein Carbonyl ELISA Kit (Cell Biolabs, Inc). All samples were run in duplicate.

\section{Statistical analysis}

The subjects were randomized into two groups: placebo $(n=3)$ and quercetin treatment $(n=5)$. Fifteen subjects were originally enrolled, however, during the normal training, three subjects acquired injuries not caused by the research design and four subjects did not meet the training requirements during the 6 week time frame. A three-way ANOVA with interactions was used to compare differences between variables. Significance for all comparisons was set at $P<0.05$. This data analysis allowed group comparisons for individual assays and performance measures. All data were analyzed using R2.13.1 (http://www.r-project.org/).

\section{Results \\ Subject characteristics}

Descriptive information regarding subjects' characteristics and $\mathrm{VO}_{2 \text { peak }}$ is presented in Table 1 .

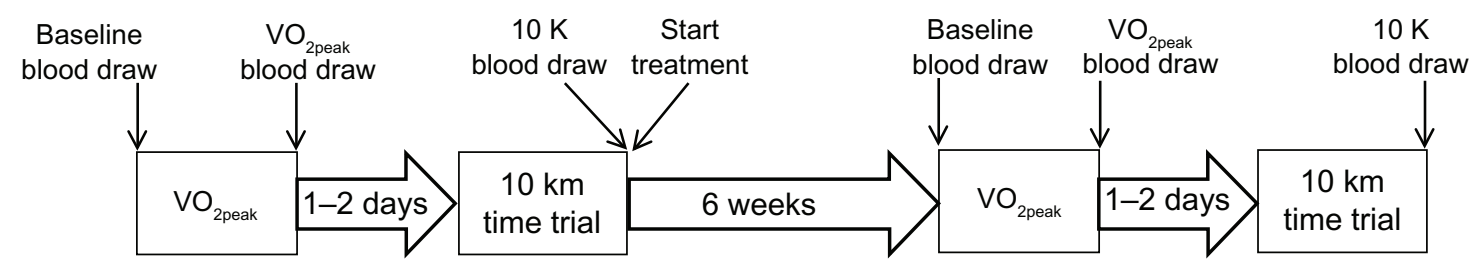

Figure I Schematic of research methods. 
Table I Subject characteristics

\begin{tabular}{llll}
\hline Group & Age (years) & Height $(\mathbf{c m})$ & BW $\mathbf{( k g )}$ \\
\hline Quercetin & $24.0 \pm 5.4$ & $175.3 \pm 5.1$ & $69.9 \pm 9.5$ \\
Placebo & $22.5 \pm 3.0$ & $171.5 \pm 4.6$ & $65.5 \pm 3.9$ \\
\hline
\end{tabular}

Note: Values are means \pm standard deviation.

\section{Performance}

In response to the 6 week training and supplementation period, the $\mathrm{VO}_{2 \text { peak }}($ Table 2 ) increased by $11 \%$ and $6.1 \%$ in the quercetin and placebo groups, respectively. However, there were no significant interactions between pre-supplementation and post-supplementation with quercetin or placebo $(P=0.172)$. The interactions were not significant for measures $3.2 \mathrm{~km}$ $(P=0.967), 6.4 \mathrm{~km}(P=0.688)$, and $9.6 \mathrm{~km}(P=0.517)$.

Similar to $\mathrm{VO}_{2 \text { peak }}$, heart rate response and RPE during the $10 \mathrm{~km}$ TT were not significantly different (Tables 3 and 4).

\section{TAC}

After 6 weeks of training there were no significant interactions between the predictive variables using TAC as the response (Table 5). When means between each of the individual predictive variables were explored, significant differences appeared between Baseline $(3.20 \pm 0.03 \mathrm{nmol} / \mathrm{mg}$ protein), $\mathrm{VO}_{2 \text { peak }}(3.28 \pm 0.03 \mathrm{nmol} / \mathrm{mg}$ protein), and $10 \mathrm{~km}$ TT $(3.54 \pm 0.02 \mathrm{nmol} / \mathrm{mg}$ protein $),(P=0.007)$. Significant differences were also found between groups quercetin $(3.20 \pm 0.06 \mathrm{nmol} / \mathrm{mg}$ protein) and placebo $(3.59 \pm 0.09 \mathrm{nmol} / \mathrm{mg}$ protein $),(P<0.001)$ when presupplementation was combined with post-supplementation. There were no significant differences between pre- and post-supplementation within groups quercetin and placebo $(P=0.095)$.

\section{MDA}

After 6 weeks of training, there was a significant interaction between predictive variables using MDA as the response (Figures 2 and 3). The quercetin group decreased the amount of serum MDA by $0.69 \pm 0.22 \mathrm{pmol} / \mathrm{mg}$ protein from pre-supplementation to post-supplementation, whereas the placebo group increased the amount of serum MDA by $0.88 \pm 0.53 \mathrm{pmol} / \mathrm{mg}$ protein during the same time $(P=0.019)$. However, no significant differences were found between Baseline (11.42 $\pm 0.30 \mathrm{pmol} / \mathrm{mg}$ protein), $\mathrm{VO}_{\text {2peak }}(11.12 \pm 0.26 \mathrm{pmol} / \mathrm{mg}$ protein $)$, and $10 \mathrm{~km} \mathrm{TT}$ $(10.73 \pm 0.35 \mathrm{pmol} / \mathrm{mg}$ protein $),(P=0.070)$ when individual predictive variables were explored. No significant differences were also found between quercetin (10.92 \pm $0.17 \mathrm{pmol} / \mathrm{mg}$ protein) and placebo $(11.38 \pm 0.38 \mathrm{pmol} / \mathrm{mg}$ protein) $(P=0.160)$ when pre-supplementation was combined with post-supplementation. There were no significant differences between pre- and post-supplementation within groups quercetin and placebo $(P=0.753)$.

\section{Protein carbonyl}

After 6 weeks of training, there were no significant interactions between the predictive variables using protein carbonyls as the response (Table 5). Significant differences appeared between Baseline $(0.92 \pm 0.03 \mathrm{nmol} / \mathrm{mg}$ protein $), \mathrm{VO}_{2 \text { peak }}$ $(0.95 \pm 0.01 \mathrm{nmol} / \mathrm{mg}$ protein $)$, and $10 \mathrm{~km} \mathrm{TT}(0.98 \pm 0.02 \mathrm{nmol} /$ mg protein $),(P=0.002)$. Significant differences also appeared between quercetin $(0.93 \pm 0.01 \mathrm{nmol} / \mathrm{mg}$ protein $)$ and placebo ( $0.98 \pm 0.01 \mathrm{nmol} / \mathrm{mg}$ protein $),(P=0.005)$ when pre-supplementation was combined with post-supplementation. There were no significant differences between pre- and post-supplementation within groups quercetin and placebo $(P=0.541)$.

Table 2 Peak oxygen consumption and rate of oxygen consumption for three distance points during a $10 \mathrm{~km}$ TT

\begin{tabular}{llll}
\hline Group & Pre-supplementation & Post-supplementation & Two way interactions, P-value \\
\hline $\mathrm{VO}_{\text {2peak }}$ & & & 0.172 \\
$\quad$ Quercetin & $59.7 \pm 3.6$ & $66.6 \pm 1.3$ & \\
Placebo & $59.0 \pm 5.3$ & $62.6 \pm 5.9$ & 0.967 \\
3.2 km VO & & & \\
Quercetin & $50.0 \pm 3.1$ & $48.8 \pm 5.2$ & 0.688 \\
Placebo & $43.0 \pm 2.6$ & $41.9 \pm 6.6$ & \\
6.4 km VO & & & 0.517 \\
Quercetin & $45.9 \pm 3.6$ & $48.9 \pm 2.7$ & \\
Placebo & $45.3 \pm 4.9$ & $45.8 \pm 4.4$ & \\
9.6 km VO & & $50.5 \pm 1.7$ & \\
Quercetin & $47.1 \pm 2.1$ & $50.2 \pm 8.8$ & \\
Placebo & $45.4 \pm 10.2$ & $505-5.8$ & \\
\hline
\end{tabular}

Notes: Values are means \pm SD. Six weeks of supplementation between pre- and post-supplementation. Abbreviations: $10 \mathrm{~km} \mathrm{TT,} 10 \mathrm{~km}$ time trial; SD, standard deviation. 
Table 3 Heart rate for three distance points during a $10 \mathrm{~km}$ TT

\begin{tabular}{llll}
\hline Group & Pre-supplementation & Post-supplementation & Two way interactions, $P$-value \\
\hline 3.2 km heart rate & & & 0.08 \\
Group Q & $169.4 \pm 6.4$ & $163.6 \pm 2.6$ & \\
Group P & $170.3 \pm 7.1$ & $166.3 \pm 4.0$ & 0.19 \\
6.4 km heart rate & $173.2 \pm 8.6$ & $167.2 \pm 6.4$ & \\
Group Q & $175.6 \pm 5.5$ & $169.0 \pm 2.6$ & 0.07 \\
Group P & & & \\
9.6 km heart rate & $175.2 \pm 5.2$ & $173.8 \pm 9.8$ & \\
Group Q & $191.4 \pm 6.4$ & $187.2 \pm 4.2$ & \\
Group P & & & \\
\hline
\end{tabular}

Notes: Values are means \pm SD. Six weeks of supplementation between pre- and post-supplementation.

Abbreviations: $10 \mathrm{~km}$ TT, $10 \mathrm{~km}$ time trial; SD, standard deviation.

\section{SOD}

After 6 weeks of training there were no significant interactions between the predictive variables using protein carbonyls as the response (Table 5). Significant differences were found between Baseline (71.45 $\pm 3.21 \mathrm{U} / \mathrm{mg}$ protein), $\mathrm{VO}_{2 \text { peak }}$ $(82.17 \pm 4.69 \mathrm{U} / \mathrm{mg}$ protein), and $10 \mathrm{kmTT}(83.66 \pm 3.63 \mathrm{U} / \mathrm{mg}$ protein), $(P=0.013)$. Significant differences also appeared between quercetin $(72.89 \pm 3.32 \mathrm{U} / \mathrm{mg}$ protein) and placebo $(89.43 \pm 2.60 \mathrm{U} / \mathrm{mg}$ protein $),(P<0.001)$ when presupplementation was combined with post-supplementation. There were no significant differences between pre- and post-supplementation within groups quercetin and placebo $(P=0.541)$.

All markers of oxidative stress and antioxidant activity are presented in Table 5. When using a three-way ANOVA with interactions, no significant differences were found.

\section{Discussion}

Our primary findings indicate that 6 weeks of dietary quercetin supplementation (1000 mg/day) did not significantly affect $\mathrm{VO}_{2 \text { peak }}$, heart rate, $\mathrm{RPE}$, or oxygen consumption during the $10 \mathrm{~km}$ TT run. A recent meta-analysis found quercetin supplementation to have a statistical benefit in endurance performance but the effect is trivial to small. ${ }^{23}$ Our results demonstrate that there is a relationship between quercetin supplementation and the statistically significant decreasing trend in the serum MDA levels following 6 weeks of supplementation and training. These findings imply that quercetin reduced oxidative stress as measured by MDA, a product of lipid peroxidation. The reduction of oxidative stress can be a mechanism through which quercetin improves aerobic performance.

Davis et $\mathrm{al}^{3}$ found that endurance capacity with quercetin supplementation in mice was associated with positive changes in markers of mitochondrial biogenesis in just 7 days of supplementation. It is possible that flavanols, including quercetin, may enhance mitochondrial biogenesis in humans, hence improve aerobic performance. Flavonol rich lychee fruit extract, has been shown to decrease inflammation caused by high intensity exercise but, as in our study, did not significantly improve aerobic performance in humans. ${ }^{24}$ Similarly, Nieman et $\mathrm{al}^{25}$ found that quercetin reduced inflammation but had no effect on cycling performance in trained cyclists.

In our study, quercetin supplementation did not enhance performance through peak oxygen consumption or running economy measured by oxygen consumption during

Table 4 RPE for three distance points during a $10 \mathrm{~km}$ TT

\begin{tabular}{llll}
\hline Group & Pre-supplementation & Post-supplementation & Two way interactions, P-value \\
\hline 3.2 km RPE & & & 0.11 \\
Group Q & $10.3 \pm 0.6$ & $12.0 \pm 1.0$ & \\
Group P & $11.5 \pm 0.3$ & $10.3 \pm 0.5$ & 0.39 \\
6.4 km RPE & $14.5 \pm 2.1$ & $14.0 \pm 1.4$ & \\
Group Q & $12.7 \pm 0.6$ & $12.7 \pm 0.6$ & 0.37 \\
Group P & & & \\
9.6 km RPE & $15.0 \pm 2.0$ & $14.7 \pm 1.5$ & \\
Group Q & $15.3 \pm 2.5$ & $15.0 \pm 2.0$ & \\
Group P & 15.3 & & \\
\hline
\end{tabular}

Notes: Values are means \pm SD. Six weeks of supplementation between pre- and post-supplementation.

Abbreviations: $10 \mathrm{~km} \mathrm{TT,} 10 \mathrm{~km}$ time trial; RPE, rating of perceived exertion; SD, standard deviation. 


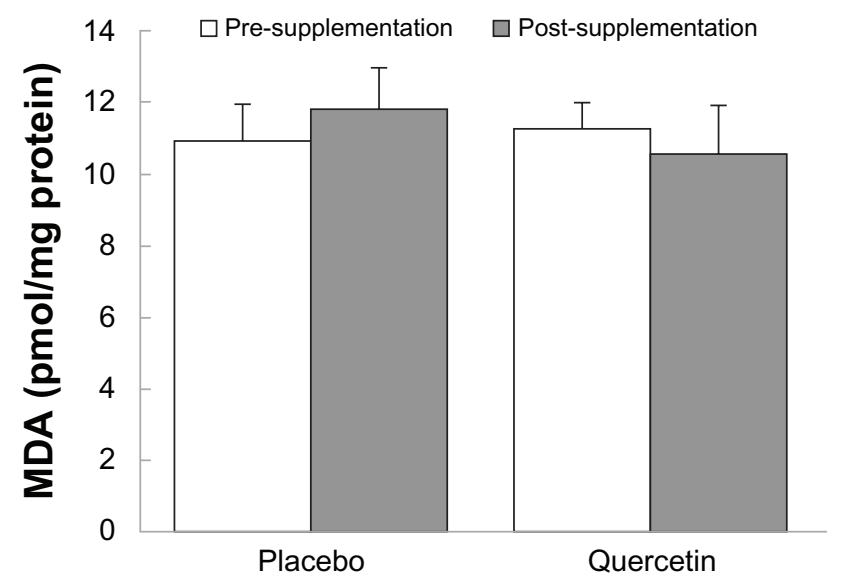

Figure 2 Pre- and post-supplementation MDA values for placebo and quercetin groups.

Notes: Mean \pm SD. The interactions between the placebo and quercetin groups with pre- and post-supplementation were significant $(P=0.019)$.

Abbreviations: MDA, malondialdehyde; SD, standard deviation.

a self-selected speed $10 \mathrm{~km}$ TT. The peak oxygen consumption results obtained are consistent with published studies on the ergogenic effect of quercetin supplementation in humans. Ganio et a $\mathrm{l}^{18}$ found that 5 days of quercetin supplementation did not improve $\mathrm{VO}_{2 \max }$ in untrained, sedentary individuals. Cureton et $\mathrm{al}^{5}$ showed that $1000 \mathrm{mg} /$ day of quercetin supplementation had no significant effect on $\mathrm{VO}_{2 \text { peak }}$ or metabolic responses during submaximal cycling. Davis et $\mathrm{al}^{21}$ demonstrated that $\mathrm{VO}_{2 \max }$ improved by $3.9 \%$ with 7 days of quercetin supplementation $(1000 \mathrm{mg} /$ day $)$ in untrained subjects. A significant difference between this study and ours is the conditioning of subjects with the subjects in the current study being well-trained versus untrained in the cited study.

According to Vollaard et $a 1,{ }^{26}$ when assessing aerobic performance, it is important to utilize a direct measure of performance output to prevent the large individual variability

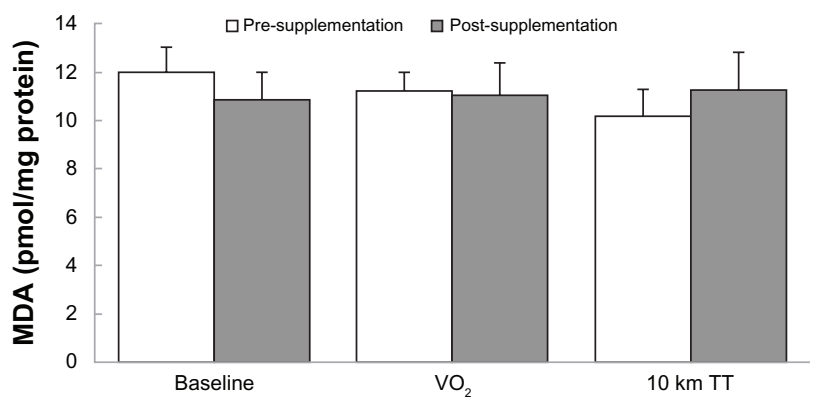

Figure 3 Pre- and post-supplementation MDA values for Baseline, $\mathrm{VO}_{2 \text { peak }}$, and $10 \mathrm{~km}$ TT groups.

Notes: Mean \pm SD. The interactions between the quercetin groups with preand post-supplementation with Baseline, $\mathrm{VO}_{2 \text { peak }}$, and $10 \mathrm{~km}$ TT were significant $(P=0.007)$.

Abbreviations: $10 \mathrm{~km} \mathrm{TT,} 10 \mathrm{~km}$ time trial; MDA, malondialdehyde; SD, standard deviation. outcome associated with a percentage of $\mathrm{VO}_{2 \text { peak }}$. Therefore, we analyzed differences in oxygen consumption at a selfselected $10 \mathrm{~km}$ TT pace from pre- to post-supplementation. A decrease in oxygen consumption indicates improved running economy, which can lead to an improved time trial performance or time to fatigue test. Consistent with the lack of changes in $\mathrm{VO}_{2 \text { peak }}$, we did not find that quercetin supplementation altered oxygen consumption at the self-selected $10 \mathrm{~km}$ TT pace.

It has been hypothesized that the antioxidant properties of quercetin may improve endurance performance by scavenging free radicals, and reducing systemic inflammation, damage to skeletal muscle's membranes and contractile proteins, and oxidative stress. ${ }^{27}$ Previous research by Hadley et $\mathrm{al}^{28}$ found an increase in urinary MDA excretion following exercise in the unsupplemented group and a decrease in urinary MDA following exercise in the supplemented (vitamins C and E) group. Similarly, we found no significant difference in serum MDA between quercetin and placebo before training. However, following training, the placebo group had an increase in serum MDA, while the quercetin group had a decrease in serum MDA, resulting in a significant interaction between the two groups with pre- and post-supplementation. This observation strongly supports our hypothesis of a decreased level of oxidative stress with quercetin supplementation. However, we did not observe any benefits in performance.

Unexpectedly, we found differences in TAC, protein carbonyl, and SOD activity between the quercetin and placebo groups. These differences were observed before and after supplementation, however, quercetin supplementation did not appear to have an effect. This may be due to subjects being randomized by $\mathrm{VO}_{2 \text { peak }}$ rather than antioxidant or oxidative levels as well as a small sample size.

We found no changes in TAC, protein carbonyl, or SOD activity with 6 weeks of training and quercetin supplementation. These results are similar to the findings of Quindry et $\mathrm{al}^{29}$ who found no alterations in post-race antioxidant capacity or oxidative damage with 3 weeks of quercetin supplementation prior to a $160 \mathrm{~km}$ endurance run, which took up to 30 hours to complete. In addition, there was no difference in performance between the supplemented and non-supplemented groups. Our findings are also similar to findings by McAnulty et al ${ }^{30}$ who supplemented trained cyclists for 3 weeks prior to a 3 day cycling bout of $57 \%$ of cyclist's $\mathrm{VO}_{2 \max }$ and demonstrated that although plasma quercetin increased, there were no changes in oxidative stress, inflammation, plasma antioxidant capacity, or performance. 
Table 5 Markers of oxidative stress and antioxidant activity

\begin{tabular}{|c|c|c|c|c|c|}
\hline & \multicolumn{2}{|l|}{ Quercetin } & \multicolumn{2}{|l|}{ Placebo } & \multirow{2}{*}{$\begin{array}{l}\text { Three way } \\
\text { interaction, } \\
P \text {-value }\end{array}$} \\
\hline & Pre-supplementation & Post-supplementation & Pre-supplementation & Post-supplementation & \\
\hline \multicolumn{6}{|c|}{ TAC, nmol/mg protein } \\
\hline Baseline & $3.22 \pm 0.12$ & $2.96 \pm 0.29$ & $3.30 \pm 0.72$ & $3.49 \pm 0.20$ & 0.513 \\
\hline $\mathrm{VO}_{2 \text { peak }}$ & $2.90 \pm 0.63$ & $3.32 \pm 0.20$ & $3.66 \pm 0.21$ & $3.77 \pm 0.22$ & \\
\hline 10 km TT & $3.40 \pm 0.22$ & $3.53 \pm 0.30$ & $3.55 \pm 0.32$ & $3.80 \pm 0.32$ & \\
\hline \multicolumn{6}{|c|}{ MDA, pmol/mg protein } \\
\hline Baseline & $11.78 \pm 1.51$ & $10.68 \pm 0.82$ & $|2.33 \pm 1.5|$ & $11.12 \pm 1.78$ & 0.181 \\
\hline $\mathrm{VO}_{2 \text { peak }}$ & $1 \mathrm{I} .62 \pm 0.72$ & $10.36 \pm 0.71$ & $10.58 \pm 0.72$ & $12.11 \pm 1.55$ & \\
\hline 10 km TT & $10.38 \pm 1.48$ & $10.67 \pm 1.06$ & $9.89 \pm 1.48$ & $12.22 \pm 2.02$ & \\
\hline \multicolumn{6}{|c|}{ Protein carbonyl, nmol/mg protein } \\
\hline Baseline & $0.93 \pm 0.02$ & $0.88 \pm 0.05$ & $0.93 \pm 0.12$ & $0.95 \pm 0.05$ & 0.589 \\
\hline $\mathrm{VO}_{2 \text { peak }}$ & $0.92 \pm 0.11$ & $0.93 \pm 0.03$ & $0.96 \pm 0.02$ & $1.01 \pm 0.04$ & \\
\hline 10 km TT & $0.96 \pm 0.03$ & $0.97 \pm 0.05$ & $0.98 \pm 0.04$ & $1.03 \pm 0.06$ & \\
\hline \multicolumn{6}{|c|}{ SOD, U/mg protein } \\
\hline Baseline & $72.29 \pm 4.82$ & $61.92 \pm 9.57$ & $83.75 \pm 21.09$ & $73.52 \pm 10.22$ & 0.396 \\
\hline $\mathrm{VO}_{2 \text { peak }}$ & $71.85 \pm 21.82$ & $72.98 \pm 10.15$ & $97.34 \pm 13.78$ & $99.46 \pm 4.61$ & \\
\hline 10 km TT & $85.49 \pm 14.36$ & $72.74 \pm 14.98$ & $89.01 \pm 11.68$ & $93.49 \pm 9.51$ & \\
\hline
\end{tabular}

Notes: Values are means \pm SD. Six weeks of supplementation between pre- and post-supplementation. The values were assessed at Baseline, following a VO ${ }_{2 \text { peak }}$ test and $10 \mathrm{~km} \mathrm{TT}$.

Abbreviations: $10 \mathrm{~km} \mathrm{TT,} 10 \mathrm{~km}$ time trial; SD, standard deviation.

The time of quercetin supplementation in our study (6 weeks) was much longer than in the study (9-16 days) by Cureton et al. ${ }^{5}$ Because $\mathrm{VO}_{\text {2peak }}$ and cellular adaptations for mitochondrial biogenesis take several weeks to improve with aerobic exercise training, ${ }^{19}$ it is possible that, with a longer treatment time, we would find changes in performance measures. However, our findings imply that 6 weeks treatment time does not provide those adaptations. Contrary to our findings, Davis et $\mathrm{a}^{21}$ found a significant improvement in $\mathrm{VO}_{2 \max }$ and endurance performance using human subjects during a cycling bout with quercetin supplementation for 7 days. The authors hypothesized that the change in performance was related to mitochondrial biogenesis, reduction of reactive oxygen's species preventing fatigue, and/or the psychostimulatory effect, which may also delay fatigue. However, the biological mechanisms as to why the performance improved were not measured in this study.

It should be noted that although excessive oxidative stress can be detrimental to exercise performance, it is also known that blocking oxidative stress can hinder adaptations in the mitochondria, therefore stifling performance. Gomez-Cabrera et a ${ }^{31}$ concluded that 8 weeks of antioxidant supplementation prevented cellular adaptations in untrained men who underwent strenuous indoor cycle training. Several researchers have used cocktails of antioxidant supplements in subjects involved in kayaking and downhill running and found an attenuation of ROS resulting in a delayed recovery of muscle function. ${ }^{13,32}$ Therefore, our null exercise performance findings may also be due to the potential negative effects of antioxidant supplements on performance.

Quercetin supplementation (1000 mg/day) has been shown to be safe and quercetin is currently a legal supplement. Further research is needed before a consensus statement can be made concerning its effectiveness. We found no performance benefits with 6 weeks of supplementation in long distance runners but did find a decrease in lipid peroxidation. The reduction of oxidative stress has been found to provide benefit to exercise performance, ${ }^{11,12}$ but has also been suggested to prevent adaptations from the stress of exercise. ${ }^{31}$

Although we found a decrease in lipid peroxidation and no improvement in endurance performance, experimental limitations hamper simple interpretations of the results. Similarly to previous research by MacRae and Mefferd, ${ }^{7}$ we restricted our sample to well-trained athletes where positive adaptations may be small and difficult to detect for those who have reached a ceiling for increasing muscle oxidative capacity due to high levels attained through training. To test for these potentially small adaptations, we used a $10 \mathrm{~km} \mathrm{TT}$ to measure the $\mathrm{VO}_{2}$, heart rate, and RPE at specified intervals which can indicate changes in performance. Although this method doesn't mimic a competitive event performance, it allowed us to control environmental factors that would normally affect race performances scheduled 6 weeks apart. There is also a 
possibility that serum indicators of lipid peroxidation may not directly correlate with those indicators in muscle tissues that are responsible for exercise performance. Future studies are needed to examine the effect of quercetin with longer supplementation durations, greater bouts of intensity, greater sample size, and more specific measures of performance.

\section{Conclusion}

Quercetin has been found to improve athletic performance but the mechanisms involved are not yet clear. The results obtained in this study demonstrated, for the first time, that quercetin supplementation during training for 6 weeks can decrease oxidative stress in well-trained endurance athletes, implying the potential for improved endurance performance.

\section{Acknowledgments}

This work was funded in part by NIH Grant Number 2 P20 RR016479 from the INBRE Program of the National Center for Research Resources. Its contents are solely the responsibility of the authors and do not necessarily represent the official views of NIH.

\section{Disclosure}

The authors report no conflicts of interest in this work.

\section{References}

1. Harwood M, Danielewska-Nikiel B, Borzelleca JF, Flamm GW, Williams GM, Lines TC. A critical review of the data related to the safety of quercetin and lack of evidence of in vivo toxicity, including lack of genotoxic/ carcinogenic properties. Food Chem Toxicol. 2007;45(11):2179-2205.

2. Bjelakovic G, Nikolova D, Gluud LL, Simonetti RG, Gluud C. Mortality in Randomized Trials of Antioxidant Supplements for Primary and Secondary Prevention: Systematic Review and Meta-analysis. JAMA. 2007;297(8):842-857.

3. Davis JM, Murphy EA, Carmichael MD. Effects of the Dietary Flavonoid Quercetin Upon Performance and Health. Curr Sports Med Rep. 2009;8(4):206-213.

4. Nieman DC. Immunonutrition support for athletes. Nutr Rev. 2008; 66(6):310-320.

5. Cureton KJ, Tomporowski PD, Singhal A, et al. Dietary quercetin supplementation is not ergogenic in untrained men. J Appl Physiol. 2009; 107(4):1095-1104.

6. Davis JM, Murphy EA, Carmichael MD, Davis B. Quercetin increases brain and muscle mitochondrial biogenesis and exercise tolerance. Am J Physiol Regul Integr Comp Physiol. 2009;296(4):R1071-R1077.

7. MacRae HSH, Mefferd KM. Dietary antioxidant supplementation combined with quercetin improves cycling time trial performance. Int J Sport Nutr Exerc Metab. 2006;16(4):405-419.

8. Nieman DC, Henson DA, Gross SJ, et al. Quercetin reduces illness but not immune perturbations after intensive exercise. Med Sci Sports Exerc. 2007;39(9):1561-1569.

9. Egert S, Wolffram S, Bosy-Westphal A, et al. Daily quercetin supplementation dose-dependently increases plasma quercetin concentrations in healthy humans. J Nutr. 2008;138(9):1615-1621.

10. Urso ML, Clarkson PM. Oxidative stress, exercise, and antioxidant supplementation. Toxicology. 2003;189(1-2):41-54.
11. Ferreira LF, Reid MB. Muscle-derived ROS and thiol regulation in muscle fatigue. J Appl Physiol. 2008;104(3):853-860.

12. Sen CK. Antioxidants in exercise nutrition. Sports Med. 2001; 31(13):891-908.

13. Close GL, Ashton T, Cable T, et al. Ascorbic acid supplementation does not attenuate post-exercise muscle soreness following muscledamaging exercise but may delay the recovery process. $\mathrm{Br} J \mathrm{Nutr}$. 2006;95(5):976-981.

14. Chen CY, Bakhiet RM, Hart V, Holtzman G. Isoflavones improve plasma homocysteine status and antioxidant defense system in healthy young men at rest but do not ameliorate oxidative stress induced by 80\% VO(2)pk exercise. Ann Nutr Metab. 2005;49(1):33-41.

15. Bigelman KA, Fan EH, Chapman DP, Freese EC, Trilk JL, Cureton KJ. Effects of six weeks of quercetin supplementation on physical performance in ROTC cadets. Mil Med. 2010;175(10):791-798.

16. Di Giacomo C, Acquaviva R, Sorrenti V, et al. Oxidative and antioxidant status in plasma of runners: effect of oral supplementation with natural antioxidants. J Med Food. 2009;12(1):145-150.

17. Dumke CL, Nieman DC, Utter AC, et al. Quercetin's effect on cycling efficiency and substrate utilization. Appl Physiol Nutr Metab. 2009;34(6):993-1000.

18. Ganio MS, Armstrong LE, Johnson EC, et al. Effect of quercetin supplementation on maximal oxygen uptake in men and women. J Sports Sci. 2010;28(2):201-208.

19. Holloszy JO, Coyle EF. Adaptations of skeletal muscle to endurance exercise and their metabolic consequences. J Appl Physiol. 1984; 56(4):831-838

20. Thompson WR, American College of Sports Medicine, Gordon NF, Pescatello LS. ACSM's Guidelines for Exercise Testing and Prescription, 8th ed. Philadelphia: Lippincott Williams \& Wilkins; 2010.

21. Davis JM, Carlstedt CJ, Chen S, Carmichael MD, Murphy EA. The Dietary Flavonoid Quercetin Increases $\mathrm{VO}_{2 \max }$ and Endurance Capacity. Int J Sport Nutr Exerc Metab. 2010;20(1):56-62.

22. Bergeron MF, Laird MD, Marinik EL, Brenner JS, Waller JL. Repeatedbout exercise in the heat in young athletes: physiological strain and perceptual responses. J Appl Physiol. 2009;106(2):476-485.

23. Kressler J, Millard-Stafford M, Warren GL. Quercetin and Endurance Exercise Capacity: A Systematic Review and Meta-analysis. Med Sci Sports Exerc. 2011;43(12):2396-2404.

24. Nishizawa M, Hara T, Miura T, et al. Supplementation with a flavanolrich lychee fruit extract influences the inflammatory status of young athletes. Phytother Res. 2011;25(10):1486-1493.

25. Nieman DC, Henson DA, Maxwell KR, et al. Effects of quercetin and EGCG on mitochondrial biogenesis and immunity. Med Sci Sports Exerc. 2009;41(7):1467-1475.

26. Vollaard NB, Constantin-Teodosiu D, Fredriksson K, et al. Systematic analysis of adaptations in aerobic capacity and submaximal energy metabolism provides a unique insight into determinants of human aerobic performance. J Appl Physiol. 2009;106(5):1479-1486.

27. Nieman DC. Quercetin's Bioactive Effects in Human Athletes. Curr Top Nutraceutical Res. 2010;8(1):33-43.

28. Hadley M, Visser MF, Vander Steen T. Antioxidant Effect on Urinary Excretion of Malondialdehyde in Non-Athletes During Aerobic Training. Int J Vitam Nutr Res. 2009;79(1):5-13.

29. Quindry JC, McAnulty SR, Hudson MB, et al. Oral Quercetin Supplementation and Blood Oxidative Capacity in Response to Ultramarathon Competition. Int J Sport Nutr Exerc Metab. 2008;18(6):601-616.

30. McAnulty SR, McAnulty LS, Nieman DC, et al. Chronic quercetin ingestion and exercise-induced oxidative damage and inflammation. Appl Physiol Nutr Metab. 2008;33(2):254-262.

31. Gomez-Cabrera MC, Domenech E, Romagnoli M, et al. Oral administration of vitamin $\mathrm{C}$ decreases muscle mitochondrial biogenesis and hampers training-induced adaptations in endurance performance. $\mathrm{Am}$ J Clin Nutr. 2008;87(1):142-149.

32. Teixeira VH, Valente HF, Casal SI, Marques AF, Moreira PA. Antioxidants Do Not Prevent Postexercise Peroxidation and May Delay Muscle Recovery. Med Sci Sports Exerc. 2009;41(9):1752-1760. 
Open Access Journal of Sports Medicine

Dovepress

\section{Publish your work in this journal}

Open Access Journal of Sports Medicine is an international, Visit http://www.dovepress.com/testimonials.php to read real quotes peer-reviewed, open access journal publishing original research, from published authors.

reports, reviews and commentaries on all areas of sports

medicine. The manuscript management system is completely

online and includes a very quick and fair peer-review system.

Submit your manuscript here: http://www.dovepress.com/open-access-journal-of-sports-medicine-journal 